Supplement of Atmos. Chem. Phys. Discuss., 15, 1523-1571, 2015

http://www.atmos-chem-phys-discuss.net/15/1523/2015/

doi:10.5194/acpd-15-1523-2015-supplement

(C) Author(s) 2015. CC Attribution 3.0 License.

(c) (i)

\title{
The climatology of dust aerosol over the arabian peninsula
}

\author{
A. Shalaby et al.
}

Correspondence to: A. Shalaby (ashalaby@ictp.it) 


\section{Supplement material}

2

3 Table S1: Geographical location and time records for the observational sites in the Arabian 4 Peninsula.

5

\begin{tabular}{llllll}
\hline Station & Latitude & Longitude & $\begin{array}{l}\text { Altitude } \\
\left(\mathrm{asl}^{*}\right)\end{array}$ & $\begin{array}{l}\text { AERONET time } \\
\text { records }\end{array}$ & Satellite Time records \\
\hline Kuwait Univ. & $29^{\circ} 19^{\prime} 30^{\prime \prime} \mathrm{N}$ & $47^{\circ} 58^{\prime} 15^{\prime \prime} \mathrm{E}$ & $42 \mathrm{~m}$ & $2008-2012$ & $2006-2012$ \\
Solar-Village & $24^{\circ} 54^{\prime} 25^{\prime \prime} \mathrm{N}$ & $46^{\circ} 23^{\prime} 49^{\prime \prime} \mathrm{E}$ & $764 \mathrm{~m}$ & $1999-2012$ & $2006-2012$ \\
Mezaira & $23^{\circ} 08^{\prime} 42^{\prime \prime} \mathrm{N}$ & $53^{\circ} 46^{\prime} 44^{\prime \prime} \mathrm{E}$ & $204 \mathrm{~m}$ & $2006-2012$ & $2006-2012$ \\
\hline
\end{tabular}

6

* above seal level

7

8

9

10

11

12

13

14

15

16

17

18

19

20

21

22 


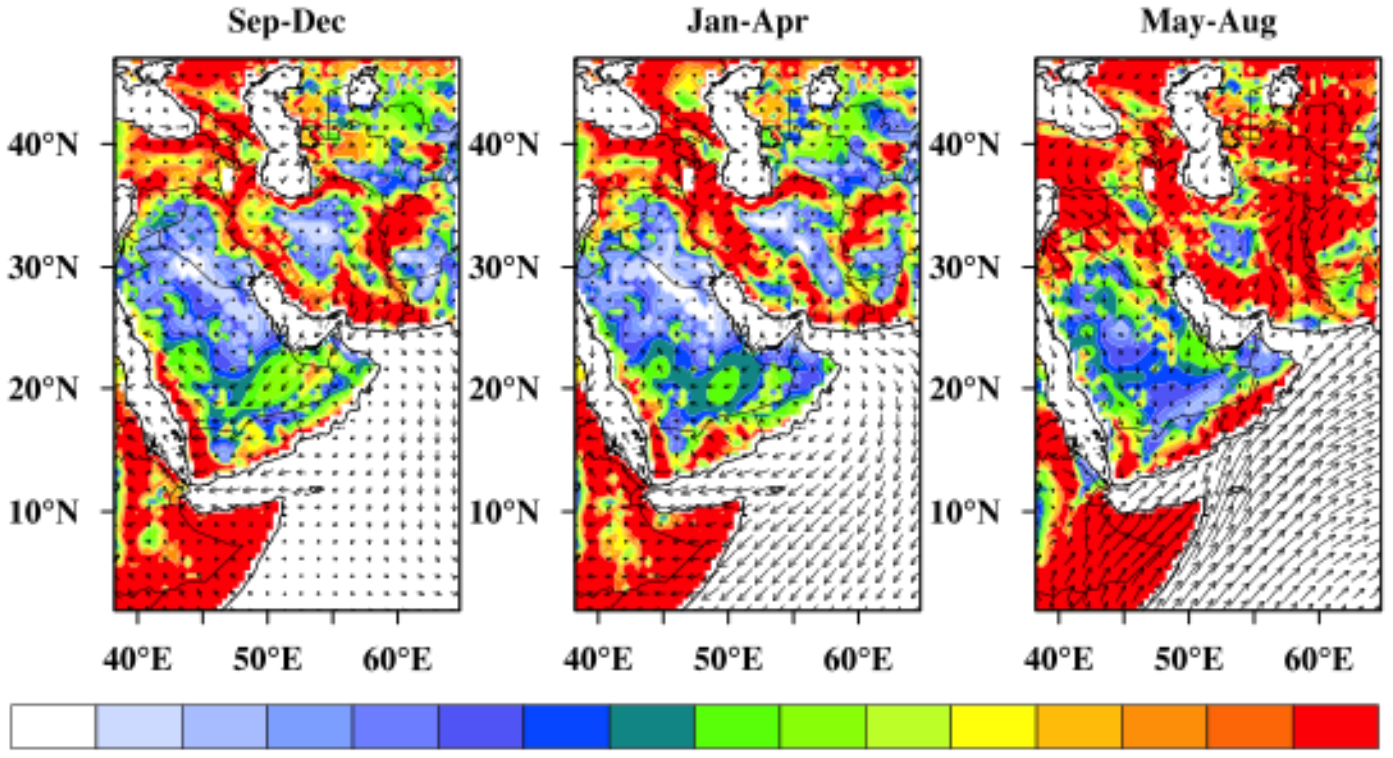

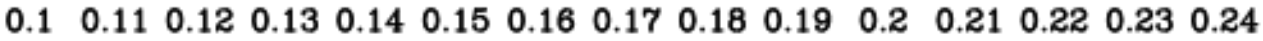

25

26 Figure S1: Climatology (seasonal average) of the friction velocity in $\mathrm{ms}^{-1}$, based on 2000-2012

27 time interval

28

29

30

31

32

33

34

35

36

37

38

39

40 


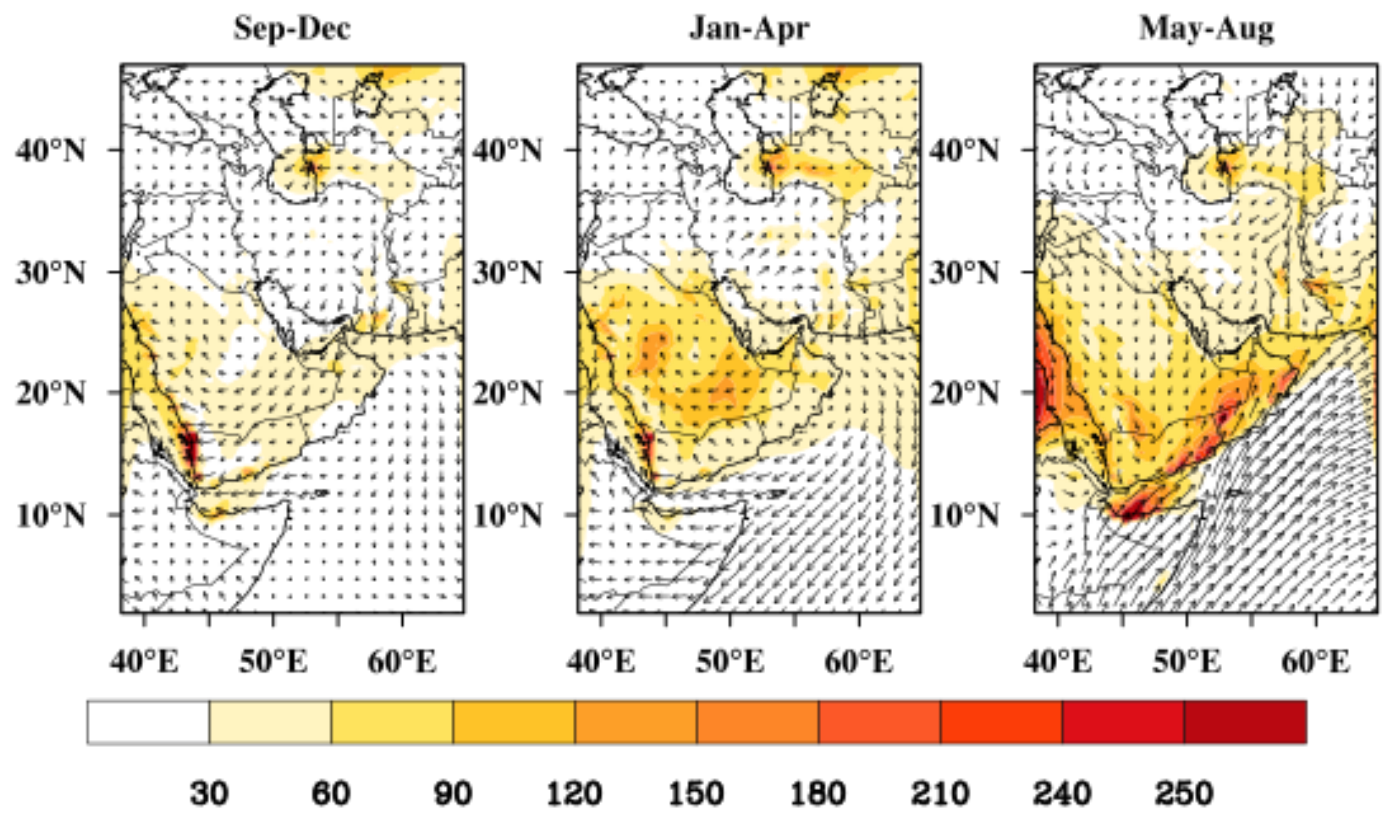

42

43 Figure S2: Climatology (seasonal average) of the atmospheric surface dust (with diameter less 44 than $10 \mu \mathrm{m})$ concentration in $\left(\mu \mathrm{g} \mathrm{m} \mathrm{m}^{-3}\right)$ based on 2000-2012 time interval. The legend is 45 concentration in $\mu \mathrm{g} \mathrm{\textrm {m } ^ { - 3 }}$

46

47

48

49

50

51

52

53

54

55 


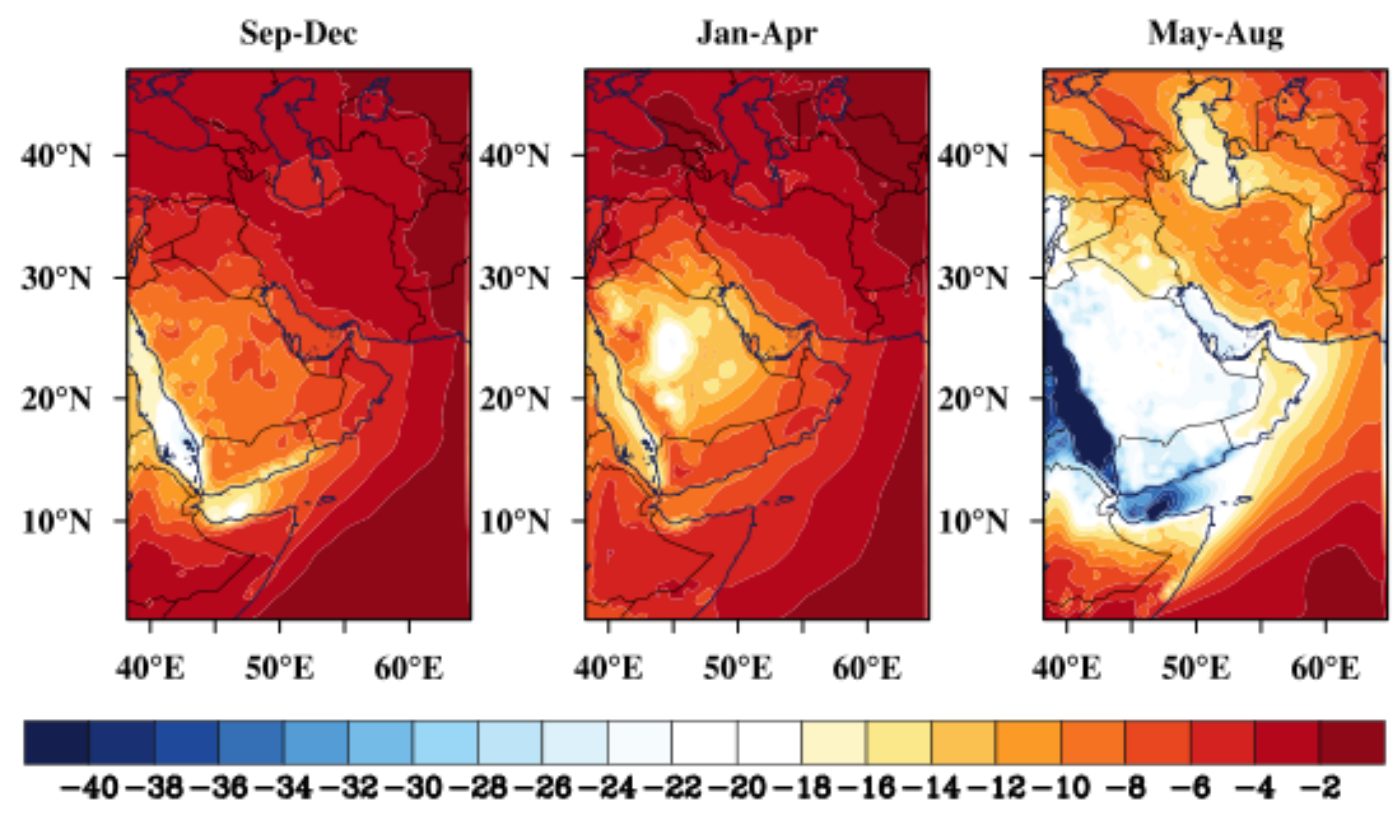

58 Figure S3: Climatology (seasonal average) of RegCM4's surface radiative forcing ( $\left.\mathrm{W} \mathrm{m}^{-2}\right)$

59 based on 2000-2012 time interval

60

61

62

63

64

65

66

67

68

69

70 
72

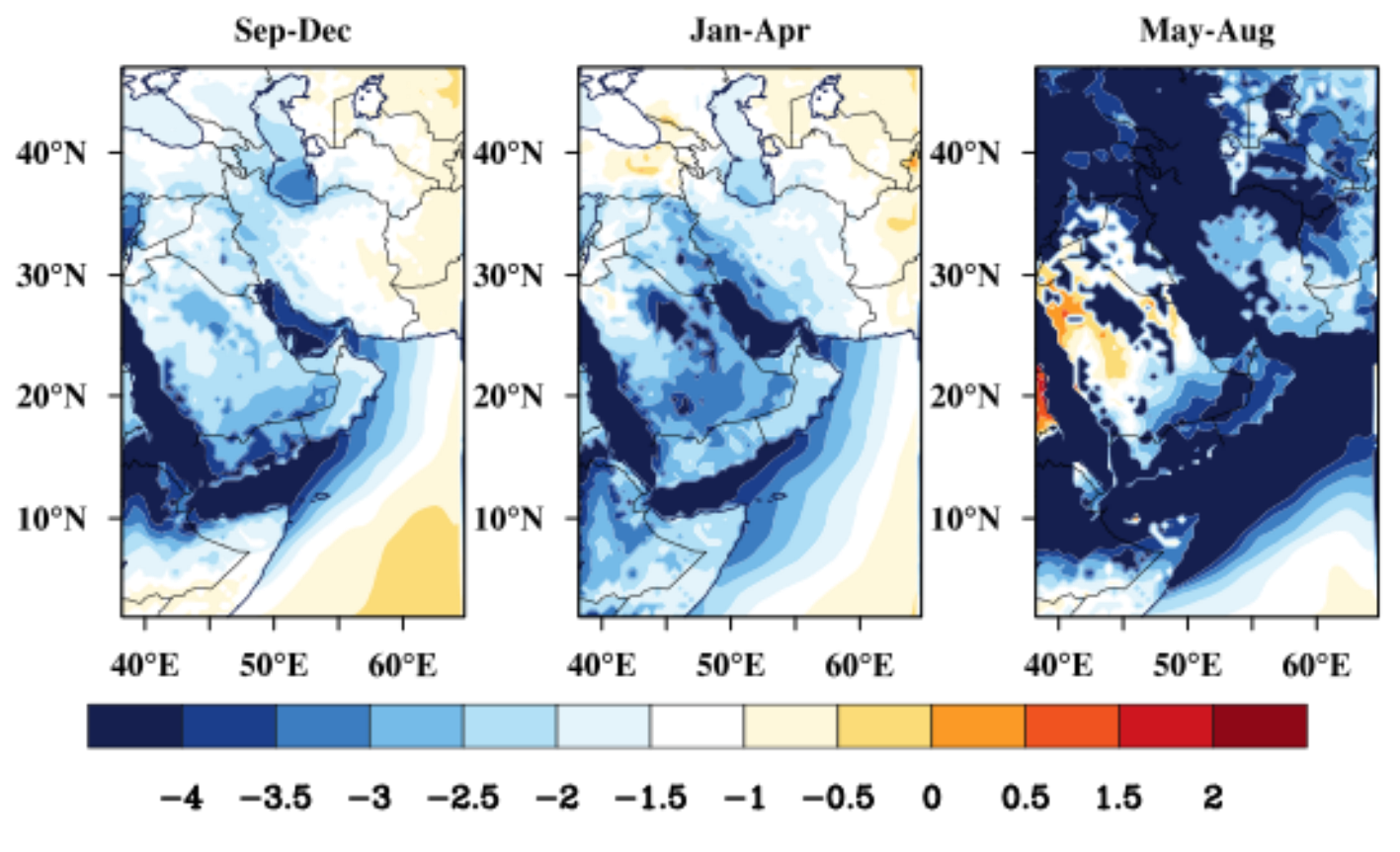

74

75 Figure S4: Climatology (seasonal average) of RegCM4's TOA radiative forcing (Wm ${ }^{-2}$ ) based 76 on 2000-2012 time interval.

77

78 